\title{
INOVAÇÃO E NOSTALGIA NO DISCURSO PUBLICITÁRIO BRASILEIRO
}

\section{INNOVATION AND NOSTALGIA IN BRAZILIAN ADVERTISING DISCOURSE}

Recebido em 04.12.2017. Aprovado em 20.12.2017

Avaliado pelo sistema double blind review

\author{
Luís Alexandre Grubits de Paula Pessôa \\ Ipessoa@iag.puc-rio.br \\ Pontifícia Universidade Católica do Rio de Janeiro (IAG/PUC-Rio) - Rio de Janeiro - RJ \\ Alessandra de Sá Mello da Costa \\ alessandra.costa@iag.puc-rio.br \\ Pontifícia Universidade Católica do Rio de Janeiro (IAG/PUC-Rio) - Rio de Janeiro - RJ \\ Flávia Barroso de Mello \\ fbmcom@hotmail.com \\ Universidade do Estado do Rio de Janeiro (PPGCOM-UERJ) - Rio de Janeiro - RJ
}

\begin{abstract}
Resumo
O presente trabalho tem como objetivo: a) compreender como os temas história, memória e tradição são apropriados pelo discurso publicitário veiculado na mídia de massa brasileira; b) explorar os sentidos depreendidos pelo consumidor a partir do discurso em questão; e c) apresentar o uso mercadológico da nostalgia como um discurso mítico que constrói sentido a partir da oposição de base tradição vs. inovação. O corpus da pesquisa foi composto por mais de quatro centenas de anúncios veiculados na Revista Veja de 2008 a 2016 e por depoimentos de consumidores coletados em 2016, por meio de dois grupos de foco. A reflexão desenvolvida neste trabalho, situada na fronteira entre os estudos de Comunicação, Marketing, Linguística e História espera enriquecer o diálogo existente entre as áreas e, sobretudo, contribuir para uma leitura mais crítica acerca dos discursos publicitários.
\end{abstract}

Palavras-chaves: Publicidade. História. Nostalgia. Memória. Semiótica.

\section{Abstract}

This article seeks to: a) understand how the themes of history, memory and tradition are made use of in the advertising discourse offered by the Brazilian mass media; b) explore the meanings awakened in consumers by the discourse in question; and c) present the market-based use of nostalgia as a mythical discourse that builds meaning based on the opposition tradition versus innovation. The data were collected from more than four hundred advertisements in the Veja magazine, from 2008 to 2016, and by testimonials taken from consumers in 2016 using focus groups. It is hoped that the ideas developed in this work, which lie on the boundaries between Communication, Marketing, Linguistics and History will help enrich the dialogue that exists between these different fields of study and, above all, contribute to a critical reading of advertising and marketing discourses as a whole.

Keywords: Advertising. History. Nostalgia. Memory. Semiotics. 


\section{Introdução}

Nos últimos anos, a literatura de Administração de empresas aponta que os temas História, Memória e Tradição vêm sendo utilizados estrategicamente por organizações como forma de fortalecer a marca e a identidade das empresas no mercado; de contribuir para a gestão de uma melhor comunicação interna e externa; e de desenvolver mecanismos que viabilizem o autoconhecimento da organização por meio do resgate de processos, princípios e valores empresariais.

De forma mais específica, este interesse também pode ser identificado na área de marketing, que se aproxima do tema a partir da apropriação do conceito de nostalgia. Marketing nostálgico, retromarketing com foco no consumidor, retrobranding e nostalgia boom são algumas manifestações da abordagem mercadológica do tema. Com efeito, o atual contexto de consumo é marcado pela globalização e por rápidas e sucessivas inovações tecnológicas que reduziram o ciclo de vida dos produtos; entretanto, de forma aparentemente paradoxal, as empresas parecem ter abraçado a influência crescente da nostalgia no desenvolvimento e no design de produtos, bem como na comunicação publicitária.

São exemplos dessa tendência produtos como o New Beetle da Volkswagen, eletrodomésticos com design retrô, MP3 players que simulam toca-discos e o revival de séries de cinema, como a continuação de Star Wars. Neste contexto, Stephen Brown, Robert V. Kozinets e John F. Sherry Jr. publicaram, em 2003, no Journal of Marketing, o artigo Teaching Old Brands New Tricks: Retro Branding and the Revival of Brand Meaning, texto fundamental para o campo de estudos denominado como marketing nostálgico. No trabalho em questão, os autores propõem o composto de marketing para a gestão de "marcas retrô ou nostálgicas" (Allegory, Arcadia, Aura e Antinomy), baseados, em especial, em uma leitura/adaptação de conceitos apresentados na obra de Walter Benjamin, pensador vinculado à escola de Frankfurt.

Dentre as diversas manifestações do discurso de marketing, este trabalho optou por analisar o discurso publicitário. Tal opção, para além da necessária delimitação operacional, origina-se na ideia de que 0 movimento de materialização e uso estratégico do passado feito pelas organizações ocorre, em grande parte, através dos meios de comunicação e tem como um de seus principais objetivos construir e fortalecer a marca, a identidade e a reputação das empresas no mercado. Nesse sentido, os meios de comunicação, ao fazerem cada vez mais usos do passado entrecruzando uma "multiplicidade de tempos", passam a ser o principal lugar de memória e de história das sociedades. E assumir que os meios de comunicação podem ser entendidos como lugares de memória, significa atribuir a estes um espaço de construção e reconstrução de uma memória socialmente compartilhada e, por isso, coletiva. Cabe observar que é de Pierre Nora (1993, 2011) - conhecido como o historiador da memória - a ideia de que existem, contemporaneamente, lugares de memória. Na perspectiva deste autor, para uma melhor compreensão acerca do que estes lugares seriam (ou poderiam ser), deve-se considerar que estes: (1) precisam ser entendidos como lugares onde se cristaliza e se refugia a própria memória; (2) pertencem, ao mesmo tempo, tanto ao domínio da memória quanto ao domínio da história; e (3) podem ser (simultaneamente, variando apenas em graus) lugares tangíveis (e/ou materiais); lugares funcionais; e lugares simbólicos.

Tendo em vista o pano de fundo apresentado, o presente trabalho tem como objetivo: a) compreender como os temas história, memória e tradição são apropriados pelo discurso publicitário veiculado na mídia de massa brasileira; b) explorar os sentidos depreendidos pelo consumidor a partir do discurso em questão; e c) apresentar o uso mercadológico da nostalgia como um discurso mítico que constrói sentido a partir da oposição de base tradição vs. inovação. 


\section{Mídia de massa, discurso publicitário e história}

Conforme discutido por Costa e Pessôa (2014), a sociedade contemporânea tem no consumo um conceito central não apenas da esfera econômica, mas, também da expressão individual e do estabelecimento das relações sociais entre os indivíduos (BELK, 1988). Nesse cenário, o discurso publicitário (aqui entendido como "a face mais visível do marketing" e como articulador de narrativas do consumo), estabelece "uma cumplicidade entre a esfera da produção com sua serialidade, impessoalidade e sequencialidade e a esfera do consumo com sua emotividade, significação e humanidade" (ROCHA, 1995).

A publicidade, no sentido concebido nos dias de hoje, emerge como fenômeno específico no século XIX, a reboque da evolução do sistema de produção capitalista. No momento de sua concepção, a publicidade concentrou-se em descrever os produtos com base em seus valores de uso e, pela força das informações e descrições elogiosas, em estimular o desejo de compra. Em meados do século XX, com a implantação da denominada "sociedade de consumo" no Ocidente, a publicidade atingiu o atual grau de relevância socioeconômica e desenvolveu, definitivamente, sua dimensão simbólica. Nesse processo, a imagem criada pela publicidade para os produtos e serviços substituiu a materialidade do objeto e as mensagens passaram a se situar preferencialmente no plano do imaginário (BAUDRILLARD, 1991).

Desse modo, a publicidade, destinada em suas origens a suscitar o consumo dos bens produzidos, convertese ela mesma em objeto de consumo: a descrição da utilidade do produto é substituída pela sua descrição afetiva e imaginária, gerenciando a distribuição social de valores - como a sofisticação, a segurança e a beleza - que permitem a classificação dos indivíduos e grupos (ROCHA, 1995; PESSÔA, 2013).

Conforme observa Carvalho (2002), a mensagem publicitária não se limita ao mundo dos sonhos, mas concilia o princípio do prazer com 0 da realidade, impondo valores, mitos, ideais e outras elaborações simbólicas, utilizando os recursos próprios da língua que the serve de veículo. Para Semprini (2006), o caráter abstrato e desmaterializado de uma parte crescente do consumo contemporâneo encontra nas marcas e na comunicação publicitária seu meio natural de expressão. Uma das principais propriedades da marca é sustentar uma rede de atributos cognitivos e simbólicos no interior da qual o produto pode encontrar um sentido e um vetor de projeção.

Pode-se, portanto, falar de um "mercado de mitos" (HOLT, 2005), caracterizado nem tanto pela competição entre produtos (e, portanto, satisfação de necessidades funcionais), mas pela competição entre identidades de marcas que oferecem ao consumidor mitos que resolvem contradições culturais. Essa mediação simbólica, uma construção linguística, é aceita como natural pelos indivíduos, o que facilita a absorção da mitologia criada ou reproduzida pela publicidade, conforme ensina Barthes (1980, 223):

$\mathrm{Na}$ realidade, aquilo que permite ao leitor consumir o mito inocentemente é o fato de ele não ver no mito um sistema semiológico, mas sim um sistema indutivo: onde existe apenas uma equivalência, ele vê uma espécie de processo causal: o significante e o significado mantêm, para ele, relações naturais. Pode-se exprimir esta confusão de um outro modo: todo o sistema semiológico é um sistema de valores; ora, 0 consumidor do mito considera a significação como um sistema de fatos: o mito é lido como um sistema factual, ao passo que é apenas um sistema semiológico.

Direcionando a análise ao tema do presente trabalho, pode-se argumentar que a narrativa publicitária que evoca a história de uma organização ou de determinada categoria de consumo constrói imagens do passado (ainda que "atualizadas" do ponto de vista tecnológico, do design ou de outra variável) que passam a ser consumidas - elas próprias, em complemento às marcas ou produtos aos quais estão a serviço - pelos indivíduos, passando a compor um imaginário do passado. De acordo com Barbosa (2007, p.16), por exemplo, pode-se pensar em cinco eixos de análise quando se busca melhor compreender a relação entre meios de comunicação e História, quais sejam:

os estudos que se utilizam de uma perspectiva meramente factual; os que priorizam as modificações e a estrutura interna dos jornais como fator de mudança do curso da história; os que enfocam os meios de comunicação como portadores de conteúdos políticos e ideológicos; os que enfatizam o contexto histórico, 
desconsiderando a dimensão interna do meio [de comunicação] e a lógica própria do universo comunicacional; e, (...) um quinto grupo que considera a dimensão processual da história e da comunicação (...) no qual ganha relevo o conteúdo, o produtor das mensagens e a forma como o público entende os sinais emitidos pelos meios.

É a partir desse quadro teórico que o projeto de pesquisa analisa a apropriação dos temas história, memória e tradição pelo discurso publicitário das organizações; neste trabalho especificamente, tomando como objeto a nostalgia nos discursos publicitários e de marketing. Na perspectiva de Rowlinson et al (2010, p.13), as corporações recorrentemente se apropriam de várias formas de memória social e coletiva da sociedade, lembrando, relembrando e legitimando o passado "em uma série de documentos e eventos organizacionais disponíveis publicamente, tais como relatórios anuais, comunicados de imprensa, páginas da web, revistas, eventos corporativos, comemorações de centenário, artefatos, produtos, lembranças, decoração e edifícios". Assim, ao veicular, na mídia de massa, campanhas publicitárias que materializam o seu passado, as organizações contribuem para os processos de construção da memória social e, também, de legitimação dos meios de comunicação como lugares de memória.

\section{Memória, história e tradição no discurso publicitário}

Na primeira etapa deste trabalho pretende-se apresentar como os temas história, memória e tradição são apropriados pelo discurso publicitário veiculado na mídia de massa brasileira. As diferentes estratégias de utilização dos temas história, memória e tradição no corpus de anúncios analisado são sintetizadas em cinco categorias (COSTA; PESSÔA, 2016): (1) a história como assinatura, (2) a história como comemoração, (3) a história como oportunidade, (4) a história como foco, e (5) a história como sustentação.

A "história como assinatura" agrupa as propagandas em que a menção temporal surge apenas como assinatura, sem relação direta com a mensagem central do anúncio, pelo uso, em especial de expressões como "desde..." ou "... x anos". Essa categoria evidencia a ideia de que a simples menção da existência de uma organização no mercado pode ser utilizada como ferramenta de gestão de comunicação e de fortalecimento da marca e da identidade da empresa. Além disso, a noção de longevidade possui atributos que vinculam a empresa a ideias como perpetuidade, permanência, continuidade, consistência.

A segunda categoria, "história como comemoração", tem como objetivo agrupar os anúncios de comemoração, como aniversários de empresas, marcos históricos na trajetória de determinados grupos empresariais, etc.

Nessa categoria percebe-se a história, a memória e a tradição como algo construído socialmente e que se materializa por meio da criação de calendários de festas e eventos comemorativos e de livros e publicações corporativas (HALBWACHS, 1992; NORA, 1993). Desse modo, constrói-se uma memória coletiva que corrobora a produção e reprodução discursiva de imagens, símbolos, mitos, estórias que sustentam valores culturais e identitários.

A "história como oportunidade" é uma categoria em que as narrativas publicitárias fazem uso de datas especiais, edições especiais de revista com algum tema específico, ou alguma outra oportunidade identificada, para fazer referências históricas da sua trajetória no mercado com relação a um tema específico.

Essa categoria evidencia a ideia de que muitas vezes as tradições são recentes, inventadas e formalmente institucionalizadas e, como desdobramento, podem ser entendidas como instrumentos que permitem que stakeholders: (a) identifiquem valores; (b) reforcem vínculos; (c) criem empatia com a trajetória da organização; (d) e reflitam sobre expectativas futuras em relação à empresa (COSTA; SARAIVA, 2011; NASSAR, 2007). Pode-se perceber que, na tentativa de criar algum vínculo com o tema (datas, mote das edições especiais, etc.), as empresas utilizam-se, por vezes, de argumentos poucos sólidos.

A quarta categoria, "história como foco", agrupa os anúncios cujas narrativas enfatizam um histórico ou tradição em determinada área. Nesse tipo de narrativa, a tradição é o principal atributo a ser destacado e/ou vendido pelo anunciante. No entanto, 
(...) a tradição resgatada nos anúncios expressa a ideia de "fazer as coisas há muito tempo" (como fabricar carros há 100 anos) e não necessariamente "fazer as coisas a muito tempo sempre da mesma maneira". A opção por tirar essa dimensão de conservadorismo do conceito de tradição talvez possa ser explicada por um possível receio das empresas em serem entendidas como inflexíveis e/ou contrárias à modernidade. Tal opção fica evidente na fórmula "tradição em inovação" (quase um oximoro), muito utilizada em várias peças publicitárias analisadas. (...) Esse processo ocorre por meio da transmissão de uma imagem discursiva publicitária de credibilidade e solidez vinculadas a noção do tempo: nos exemplos selecionados busca-se um contraste entre consumidores de tempos históricos diferentes (COSTA; PESSÔA, 2016, p.29). .

Assim, em muitos dos anúncios selecionados, nota-se a presença de fotos antigas e atuais em uma mesma peça, com pessoas de diferentes décadas utilizando os produtos da empresa, passando simultaneamente as ideias de tradição e contemporaneidade daquela marca ou de um produto.

A quinta e última categoria é a "história como sustentação". Essa categoria tem por objetivo expressar os anúncios nos quais a tradição é a sustentação ou comprovação de outro atributo que seria o foco central da narrativa. Pode-se observar que, nesse caso, a tradição apresenta diferentes níveis de importância. Pode ser o grande sustentáculo/comprovação de um posicionamento mercadológico ou, simplesmente, mais um atributo citado. Seu principal fundamento teórico norteador é que a história pode ser entendida como um processo estratégico e legitimador das práticas de gestão (ROWLINSON et al., 2010).

\section{0 discurso do consumidor}

Nesta etapa da pesquisa, pretende-se explorar os sentidos depreendidos pelo consumidor a partir do discurso em análise. Partindo do princípio de que os meios de comunicação são lugares de memória e que as organizações fazem uso de seu passado de forma estratégica em seus discursos publicitários, verificouse por meio de dois grupos de foco como as categorias criadas na etapa anterior são percebidas pelos consumidores.

Cada grupo de foco contou com nove participantes e três mediadores (dentre eles os autores do presente texto). O primeiro grupo foi composto por alunos de pós - graduação de diversos departamentos da PUCRio, com idades variadas, entre 20 e 60 anos. Já o segundo foi composto por sujeitos mais jovens, na faixa dos 20 anos, alunos de graduação da mesma instituição. A discussão foi conduzida a partir de roteiro semiestruturado e os participantes receberam cópias dos anúncios mais representativos do corpus da pesquisa para que pudessem debater o tema, como demonstra as figuras 1 e 2. Ambos foram realizados no segundo semestre de 2016, seguindo os protocolos de pesquisa qualitativa em administração. 


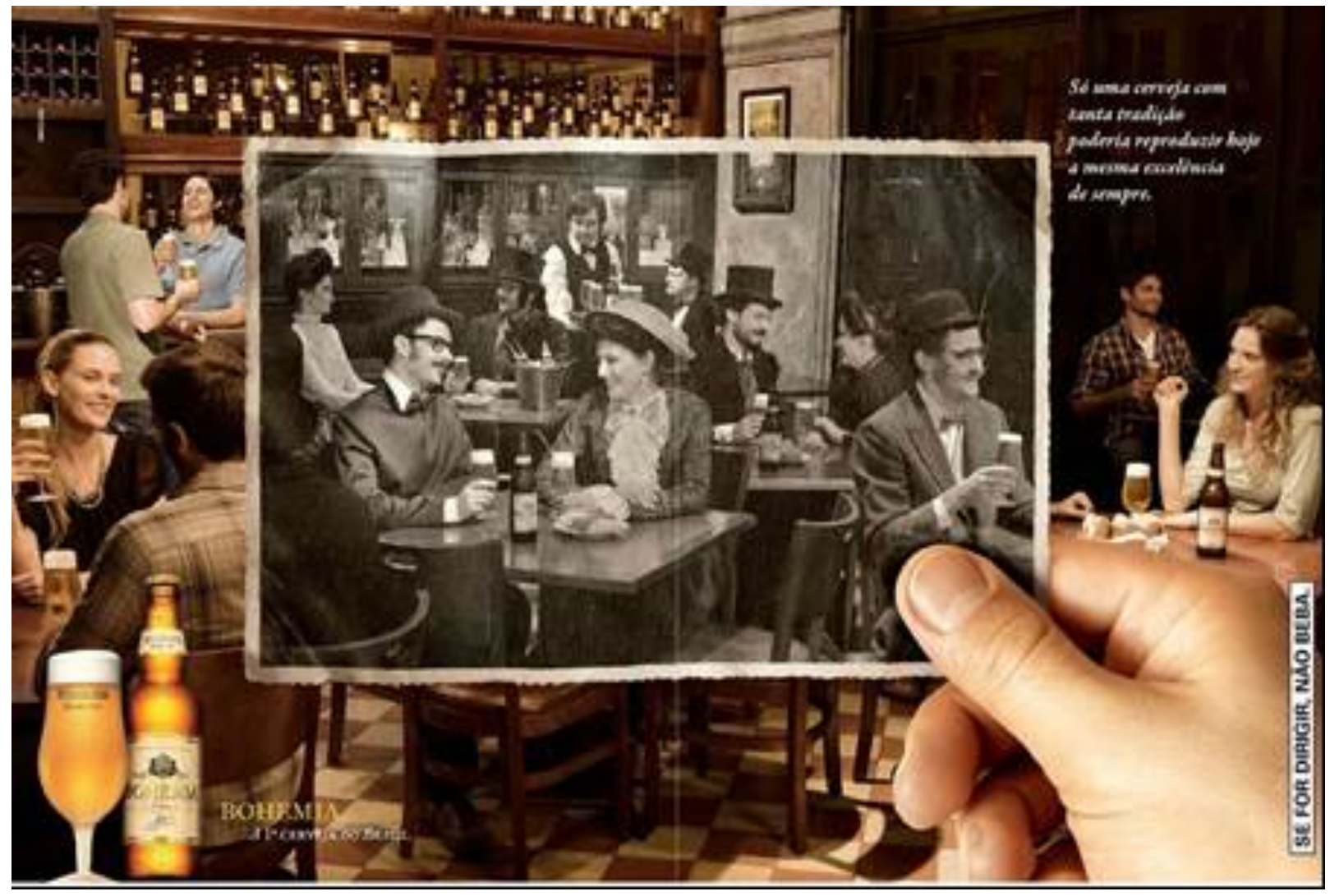

Figura 1: Anúncio da Bohemia apresentado aos participantes do grupo focal.

Fonte: Revista Veja, ed. 2178, 2010. 


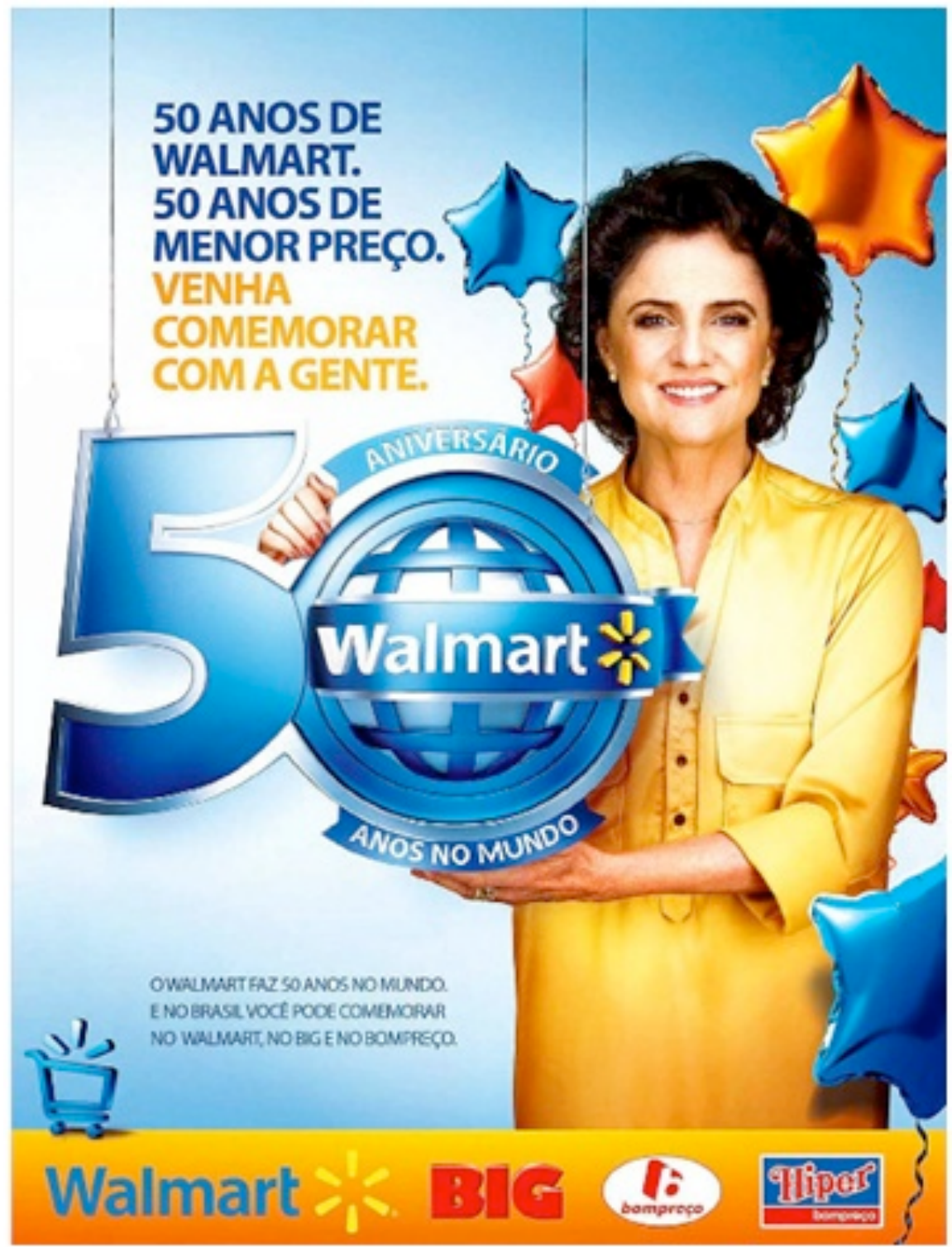

Figura 1: Anúncio do Supermercado Walmart apresentado aos participantes do grupo focal.

Fonte: Revista Veja, ed. ed. 2291, 2012.

Ambos foram realizados no segundo semestre de 2016, seguindo os protocolos de pesquisa qualitativa em administração.

Os resultados dessa etapa da pesquisa permitem observar que algumas categorias são identificadas pelos participantes antes mesmo de serem apresentadas formalmente pelos mediadores; enquanto outras sequer têm suas menções aos temas história e memória percebidas.

Na categoria "história como assinatura", a assinatura das empresas em relação ao seu tempo de mercado passaram despercebidas em ambos os grupos. Já as peças da categoria "história como foco" foram as primeiras, em ambos os grupos, a chamar a atenção dentre os dez anúncios que faziam parte do set de propagandas escolhidas para compor o material de estímulo. Para os participantes, os temas história, memória e tradição estão claros no discurso das peças desta última categoria. Afirmam, ainda, que há um "dinamismo na junção do futuro e do passado". Essa dinâmica indica, na perspectiva do consumidor, a solução do paradoxo tradição vs. modernidade que será objeto da próxima seção do texto.

Destaca-se que, para ambos os grupos, o discurso aparentemente paradoxal de "tradição com inovação" não se mostra um problema. Os sujeitos pesquisados percebem como positiva a "atualização" das marcas, a junção da tradição que carregam ("Há x anos no mercado...") com novas tecnologias que oferecem ao 
consumidor ao longo dos anos.

Alguns participantes (novamente de ambos os grupos) apontam a diferença entre o que seria uma marca ou produto "velha(o)" e "tradicional". Os sujeitos avaliam positivamente o "tradicional", a permanência ao longo dos anos, mas, desde que haja uma atualização aos padrões contemporâneos. Os participantes deixam claro que sem atualização tecnológica e inovação ("todos os recursos que existem na atualidade"), eles não continuariam a consumir as marcas ou produtos.

Outra questão levantada nesta etapa do trabalho diz respeito ao sentimento de nostalgia por parte dos sujeitos de pesquisa. Não se pode afirmar se por questões geracionais ou de ciclo de vida os participantes do segundo grupo não demonstram marcas desse sentimento em seus discursos. Observam-se alguns traços de nostalgia em relação a comidas ou brinquedos (citados espontaneamente), mas não induzidos pelos anúncios analisados. Por outro lado, o primeiro grupo se mostra mais nostálgico, identificando-se com os discursos das peças publicitárias, por meio de memórias individuais e coletivas.

Apesar da nostalgia não estar presente no discurso do segundo grupo, seus participantes chamam atenção para a categoria de "sustentação". Após diversas provocações pelos mediadores (pois o tema não surgiu espontaneamente), percebeu-se que a tradição não é um fator de decisão de compra forte para esse grupo, ainda que identificassem a credibilidade que está ligada a ela.

Os grupos também foram questionados sobre o possível sentimento de falsidade em relação ao discurso dos anúncios da categoria "história como oportunidade". Nessa categoria, percebeu-se, em alguns casos, a tentativa de criar vínculos históricos utilizando argumentos poucos sólidos. Quando Ihes foi questionado sobre essa falta de solidez, ambos os grupos afirmaram que não se sentiram enganados ou que o discurso parecesse falso. Acreditam que, no contexto em que está inserida, a mensagem é aceitável, não constituindo algo negativo na visão dos consumidores.

\section{0 "marketing nostálgico" como um discurso mítico}

Finalmente, nesta seção, pretende-se apresentar o uso mercadológico da nostalgia como um discurso mítico que constrói sentido a partir da oposição de base tradição vs. inovação. Entretanto, é necessário, inicialmente, problematizar o conceito de "marketing nostálgico" conforme apresentado na literatura de marketing.

Brown et al. (2003) propõem o composto de marketing (Allegory, Arcadia, Aura e Antinomy) para a gestão de "marcas retrô ou nostálgicas", baseados, em especial, em uma leitura de conceitos apresentados na obra de Walter Benjamin, pensador vinculado à escola de Frankfurt. Um primeiro desafio seria, portanto, discutir a apropriação dos conceitos de Benjamin pelos autores, apontando possíveis problemas na transposição feita pelos autores do pensamento do filósofo alemão para o contexto contemporâneo de mercado.

Com efeito, os autores citados baseiam-se em especial nos conceitos apresentados por Benjamin (2000) no texto seminal A obra de arte na época de sua reprodutibilidade técnica, publicado originalmente em 1936. Ainda que Brown et al. (2003) tenham observado e respeitado a grande distância entre os contextos enunciativos da obra de Benjamin e sua proposição de composto do marketing nostálgico, haveriam os autores cometido o erro de descontextualizar o pensamento do filósofo alemão?

A análise em questão apresenta-se complexa, pois, além das "obras de arte", os objetos cotidianos, os bens de consumo, as tecnologias ultrapassadas e mesmo certos modismos esquecidos, também foram alvo da atenção de Benjamin. Considerando-se o pensamento de Benjamin como representativo das primeiras décadas do Séc. XX (o autor nasceu em 1892 e suicidou-se em 1940), quando o capitalismo já apresentava parte de sua configuração atual (sendo o autor alemão um crítico severo deste sistema), poder-se-ia questionar a transposição conceitual operada por Brown et al (2003). Apesar dos autores do presente texto considerarem importante pontuar a questão, não se pretende, aqui, avaliar a pertinência teórica da proposição do composto de marketing nostálgico.

O caminho escolhido foi o de apresentar uma leitura semiótica do "marketing nostálgico". Para entender a 
proposta, é necessário retomar a definição dos termos do composto do marketing nostálgico segundo Brown et al. (2003), quais sejam:

- Alegoria: alegorias de marca (ou de marketing) são narrativas simbólicas ou metáforas estendidas. A alegoria é frequentemente usada em publicidade ao promover histórias didáticas que evocam e oferecem resoluções para estados de conflito moral do consumidor. As alegorias são dinâmicas, se alteram em resposta aos gostos e tendências populares.

- Arcadia: evocação de um sentido "quase utópico" em relação a mundos e comunidades do passado. A ideia do passado como um tempo especial, um "lugar" mágico, ainda que atualizado pela mais recente tecnologia, é parte integrante do marketing nostálgico.

- Aura: diz respeito à presença de um poderoso sentido de "autenticidade" da marca. De maneira geral, a busca dos consumidores por autenticidade é um dos pilares do marketing contemporâneo, sendo a essência das marcas percebida pelos consumidores por seus atributos considerados únicos, algo que faz parte do "DNA distintivo" de uma marca. No marketing nostálgico, a aura se apresenta na forma como o consumidor dialoga e confronta as marcas nostálgicas com sua autenticidade, seu passado e sua essência.

- Antinomia: paradoxo não passível de solução "que repousa no coração da filosofia de Benjamin". O filósofo considerava o progresso científico e tecnológico inexorável como a causa fundamental do desejo humano de retornar a tempos mais simples, mais lentos e menos estressantes. No marketing nostálgico, este paradoxo inerente se reflete na presença simultânea do novo e do velho, da tradição e da tecnologia, do primitivismo e do progresso, do igual e do diferente.

O conceito central para a leitura semiótica do marketing nostálgico seria a "Antinomia". Ainda que se possa argumentar a favor da proposição de um paradoxo não passível de solução no pensamento de Benjamin, 0 discurso publicitário - sob o prisma da semiótica greimasiana - não raro se apresenta como um discurso mítico, no sentido proposto por Claude Lévi-Strauss, e utilizado por Greimas, de um discurso no qual a lógica narrativa visa a estabelecer a conciliação de dois termos contrários de uma categoria. Portanto, os autores do presente texto defendem que o marketing nostálgico, entendido como discurso, conciliaria a tradição e a modernidade, resolvendo o paradoxo apontado por Brown et al (2003).

Tal interpretação dialoga com outros trabalhos. Floch (1990), em seu estudo da publicidade francesa de automóveis apresenta exemplo cabal dessa lógica. Mais recentemente, Pessôa (2013), inspirado em Floch (1990), discute o caso da publicidade brasileira de seguros.

A dificuldade dessa etapa do trabalho está na "separação metodológica" entre o pensamento de Benjamin (que supostamente apontaria para o paradoxo insolúvel), a interpretação dessas ideias por Brown et al (2003) e, finalmente, o entendimento do marketing nostálgico como um discurso mítico. Tendo em vista que os autores de marketing citados não adotam a perspectiva da semiótica greimasiana, deve-se tomar as devidas precauções para que os mesmos não sejam criticados a partir de um pressuposto epistemológico estranho ao seu trabalho, apontando para um vício de "descontextualização". Finalmente, vale observar que a oposição tradição vs. modernidade é fundamental no debate das ciências sociais e humanas, tema que será aprofundado em etapas posteriores desta pesquisa.

\section{Considerações finais}

No contexto do projeto de pesquisa "História, memória e tradição no discurso publicitário", coordenado pelos autores do artigo, o presente trabalho teve como objetivo compreender como os temas história, memória e tradição são apropriados pelo discurso publicitário veiculado na mídia de massa brasileira; explorar os sentidos depreendidos pelo consumidor a partir do discurso em questão; e, finalmente, apresentar o uso mercadológico da nostalgia como um discurso mítico que constrói sentido a partir da oposição de base tradição vs. inovação. 0 corpus da pesquisa foi composto por mais de quatro centenas de anúncios veiculados na Revista Veja, desde 2008 aos dias de hoje, e por depoimentos de consumidores coletados, em 2016, por meio de grupos de foco.

As análises realizadas à partir dos dados coletados conduziram à organização do corpus de anúncios em cinco categorias de utilização dos temas da história, da memória e da tradição como um conteúdo relevante 
de comunicação: a história como assinatura; a história como comemoração; a história como oportunidade; a história como foco; e a história como sustentação. Ao mesmo tempo, como desdobramento da análise das peças publicitárias, parece possível afirmar que os meios de comunicação podem ser compreendidos como expressão de lugares de memória, fortalecendo o pressuposto inicial do estudo. E lugares de memória com especificidades da contemporaneidade, quais sejam: os indivíduos consumidores são levados a percorrer trajetórias históricas (contextos, paisagens, situações, rastros e experiências do passado) a partir de perspectivas e narrativas de consumo. Ressalta-se, também, que o percurso desses consumidores não é pavimentado apenas pelos anúncios, mas, também, pelo diálogo da publicidade com outros discursos da indústria cultural.

Já do ponto de vista do discurso dos consumidores, as falas sobre o tema são marcadas mais pela reflexão sobre a credibilidade dos anúncios e a longevidade das organizações do que por traços de nostalgia. Observou-se, também, que a conciliação entre a tradição e a inovação foi considerada "natural" pelos sujeitos pesquisados, o que reforça o pressuposto inicial da pesquisa acerca do caráter mítico do discurso publicitário em questão. A reflexão desenvolvida neste trabalho, situada na fronteira entre os estudos de Linguística, História, Comunicação e Marketing, espera enriquecer o diálogo existente entre as áreas e, sobretudo, contribuir para uma leitura mais crítica acerca dos discursos publicitários.

\section{Referências}

Barbosa, M. (2007). Meios de comunicação e história: um universo de possíveis. In L. M. . Ribeiro, A.P.G.; Ferreira (Ed.), Mídia e memória: a produção de sentidos nos meios de comunicação. Rio de Janeiro: Mauad $X$.

Barthes, R. (1980). Mitologias. São Paulo: DIFEL.

Baudrillard, J. (1991). A sociedade de consumo. Rio de Janeiro: Edições 70.

Belk, R. W. (1988). Possessions and the extended self. Journal of Consumer Research, 15(2), 139-168.

Benjamin, W. (1982). A obra de arte na época de sua reprodutibilidade técnica. In L. Lima (Ed.), Org. Teoria da cultura de massa. Rio de Janeiro: Paz e Terra.

Brown, S., Kozinets, R. V, \& Sherry Jr, J. F. (2003). Teaching old brands new tricks: Retro branding and the revival of brand meaning. Journal of Marketing, 67(3), 19-33.

Carvalho, N. (2002). Publicidade: a linguagem da sedução. São Paulo: Atica.

Costa, A.S.M; Pessoa, L.A.G.P. (2014). Os Meios de Comunicação como um Lugar de Memória? História, Memória e Tradição no Discurso Publicitário na Revista Veja. Anais Do XXXVIII Encontro Da ANPAD.

Costa, A.S.M.; Pessôa, L.A.G.P. (2016). História e Memória no Discurso Publicitário na Revista Veja. Revista Pensamento Contemporâneo Em Administração, 10(1), 19.

Costa, A.S.M. ; Saraiva, L.A.S. (2011). Memória e formalização social do passado nas organizações. Revista de Administração Pública, 45(6), 1761-1780.

Floch, J.-M. (1990). Sémiotique, marketing et communication: sous les signes, les stratégies. Presses Universitaires de France.

Halbwachs, M. (1992). On collective memory. University of Chicago Press.

Holt, D. B. (2005). Como as marcas se tornam ícones: os princípios do branding cultural. São Paulo: Cultrix. Nora, P. (1993). Between memory and history: Les lieux de mémoire. In Representations (p. 26). University of California Press.

Nora, P. (2011). Reasons for the current upsurge in memory. In D. Olick, J.K.; Vinitzky-Seroussi, V.; Levy (Ed.), The Collective Memory Reader. Oxford University Press.

Oliveira, P. R. N. (2007). Relações Públicas: na construção da responsabilidade histórica e no resgate da 
memória institucional das organizações. São Caetano do Sul: Difusão Editora.

Pessoa, L. A. (2013). Narrativas da segurança no discurso publicitário: um estudo semiótico. São Paulo: Editora Mackenzie.

Rocha, E. P. G. (1995). A sociedade do sonho: comunicação, cultura e consumo. Mauad Editora Ltda.

Rowlinson, M., Booth, C., Clark, P., Delahaye, A., \& Procter, S. (2010). Social remembering and organizational memory. Organization Studies, 31(1), 69-87.

Semprini, A. (2006). A marca pós-moderna: poder e fragilidade da marca na sociedade contemporânea. São

Paulo: Estação das Letras. 